\title{
Future Orientation and Perceived Parenting of Adolescents in Two Areas with Different Association to Arts and Culture in Bandung Regency: A Comparative Study
}

\author{
$1^{\text {st }}$ Yanti Rubiyanti \\ Fakultas Psikologi \\ Universitas Padjadjaran \\ Jalan Raya Bandung Sumedang KM 21 \\ Sumedang, West Java, Indonesia \\ yanti.rubiyanti@unpad.ac.id \\ $4^{\text {th }}$ Hendriati Agustiani \\ Fakultas Psikologi \\ Universitas Padjadjaran \\ Jalan Raya Bandung Sumedang KM 21 \\ Sumedang, West Java, Indonesia
}

\author{
$2^{\text {nd }}$ Ratna Jatnika \\ Fakultas Psikologi \\ Universitas Padjadjaran \\ Jalan Raya Bandung Sumedang KM 21 \\ Sumedang, West Java, Indonesia
}

\author{
$3^{\text {rd }}$ Ahmad Gimmy Prathama \\ Fakultas Psikologi \\ Universitas Padjadjaran \\ Jalan Raya Bandung Sumedang KM 21 \\ Sumedang, West Java, Indonesia
}

\begin{abstract}
In the Bandung regency, the number of adolescents studying at the high school and university level is very low. Most of Bandung Regency is rural areas, which are far from densely populated areas in a city. The number of high schools and universities is far less than the city of Bandung. In this study, research was conducted in areas that have two different characteristics. Based on preliminary study results obtained data that adolescents who live in areas of arts and culture on average do not continue their education to higher education. Based on literature studies, factors that influence adolescents continuing education are future orientation and parenting. Therefore, this study aims to see whether there are differences in future orientation and perceived parenting in adolescents in areas with two different characteristics. Future orientation will systematically direct adolescents to have a picture in the future. The method was comparative study to measure future orientation and perceived parenting of adolescents in two areas with different association. The research subject was 196 students who attend $11^{\text {th }}$ grade senior high school (37\% male and $67 \%$ female), aged between 16 to 18 years old, which in agreement with grade 11 or adolescent period proposed by Santrock (2007), Newman \& Newman (2015) and Steinberg (2013). Participants were asked to fill in 2 questionnaire, i.e. perceived parenting and future orientation questionnaire. The result is in Jelekong, the average empirical value of father perceived parenting is $\mathbf{2 . 3 2}$, meaning that it is lower than the hypothetical average so that father parenting is perceived to be low. The average value of mother perceived parenting empirically is $\mathbf{2 . 3 6}$, meaning that it is lower than the hypothetical mean and therefore mother's perceived parenting
\end{abstract}

is low. The empirical average value of the future orientation is 2.73, meaning that it is lower than the hypothetical average and thus the future orientation is low. Whereas in Arjasari, the average empirical value of father perceived parenting is $\mathbf{2 . 2 6}$, meaning that it is lower than the hypothetical average so that father parenting is perceived to be low. The average value of empirical mother perceived parenting is 2.53 , meaning that it is higher than the hypothetical mean and therefore mother perceived parenting is high. The empirical average value of the future orientation is $\mathbf{3 . 0 3}$, meaning that it is higher than the hypothetical average and thus the future orientation is high. The comparative study showed that comparing similiraties and differences to look for what factors can cause to future orientation and perceived parenting of adolescent in two area different association. Therefore, we conclude that the perceived parenting and future orientation of adolescent in Arjasari more higher than Jelekong.

Keywords-future orientation, perceived parenting, adolescent, comparative, Indonesia

\section{INTRODUCTION}

Adolescents are the productive age group, aged $12-24$ years, according to Newman and Newman, consisting of early adolescents, aged $12-18$ years and late adolescents aged $18-24$ years. According to Newman and Newman (2015), in adolescents, a person starts thinking about himself and his world in a new way that is reflected by expanding awareness, controlling his thinking, integrating information 
from various sources and focusing more on planning and behavior that lead to goals and future strategy.

The number of adolescents in Bandung regency is around $17 \%$ of the total of population of Bandung which is 2.412.458 peoples (Biro Pusat Statistik or Central Bureau of Statistics), 2018). Adolescents as productive age and the time when the task of development is to plan for the future to achieve a good life in the future.

The demographic dividend, Indonesia can benefit and have the opportunity to increase productivity of its people. However, data from (Lembaga Ilmu dan Pengetahuan Indonesia or The academy of science) LIPI's research results (2016) show that the quality and work skills of the labor force in Indonesia are relatively low and are less competitive. West Java is the province with the largest population and Bandung is on of the regions with the largest population. Bandung represents the largest ethnic group after the Javanese tribe. (BPS, 2018).

Related to demographic dividend, preparing the adolescents in the future becomes important. In the study of Psychology, one of the concepts that discuss planning the future is the future orientation (i.e, FO). According to Seginer (2009), FO will provide a systematic and scientific description to adolescents to have motivation and expectation in the future as a provision for designing their future, both in the education and career and work. Factors that influence of FO are internal factors and external factors.

The result of the interview showed the fact that about 900 adolescents were active in the painting area in Jelekong Bandung. The adolescents who are active in this painting area generally do not continue school after graduating from Junior High School and unemployed. Based on the results on interview with village head of Jelekong, about 1500 adolescents in Jelekong unemployed. Another fact shows that about $70 \%$ of adolescents are less interested in continuing their advanced studies to high school or vocational school. The highest formal education achieved is graduating from junior high school. The reasons for not continuing education are due to cost factors, lack of figures who are highly educated in the family, lack of interest in school, stronger environmental influences and willingness to work directly in puppet and painting art studios.

Jelekong in Bandung regency is one of area with low number of adolescent that continue their education to high level, and therefore they mostly work in informal area, especially in Sundanese cultural arts area. Their income is mostly insufficient for their daily needs. To gain better life, during their adolescent period, one should design their future. Parents have a very crucial impact on designing their children future orientation. Therefore in the present study the influence of parent support on motivation and interest of their children in Jelekong will be investigated.

Jelekong is referred to as village of painters and has a famous puppet hermitage (Padepokan Wayang). This painter village has developed since 1970 and has been passed down from generation to generation to the present. Many adolescence actively participate as painters, both painters with beginners, middle class and upper class. While the art of golek's puppet developed since 1920. In Jelekong, there are two famous puppeteer $n$ Indonesia even to the International world.

The phenomena of the adolescents not going to school/ dropping out of school, not interested to continuing further education and unemployment in large enough numbers is a big problem in Indonesia. Especially in Bandung regency. Data from Unicef in 2016 as many as 2,5 million Indonesia adolescents cannot enjoy futher education, which is as many 600 thousand elementary school aged (SD) and 1,9 million junior high school aged adolescents. This condition if it is sustainable, it will harm the Indonesia nation, where adolescence who are supposed to be supporters of the nations's hope, what happens to adolescents become obtacles to the progress of the nation. This is the basis of interest in research related to psychological factors, namely Future Orientation. Future orientation in adolescents is important for adolescents to be able to set goals and plan for their future and develop mental health behaviors. (Lindstorm, Sarah Johnson, etc. 2014). The other studies explain that there is a significant relationship between family factors and future orientation. (McCabe, Kristen M. Barnett, Douglass, 2000 )

Future Orientation is influenced by internal and external factors. Theoretically, Nurmi (1991) posited that parents are important influences on their adolescents' future orientation by setting the normative standards affecting their children's values, interests and goals. In addition, parents serve as role models for their adolescents and they foster their adolescents' attributions regarding the ability to influence domains of life (such as the educational domain). In addition to the context that parents provide for adolescents' future orientation, Nurmi also theorized that how adolescents feel about themselves has implications for their future orientation. In fact, he stated that a major influence on adolescents' future orientation was "internal beliefs in their own influence over the future', The phenomenon in Jelekong, shows that parents are one of the factors that influence how adolescence plan their future, both of their education or career. Theoretically, there are 4 dimensions in parenting. The four dimensions of parenting is acceptance, supervision, autonomy granting and limit setting. In this study, adolescents perceived parenting in supporting adolescents to plan their future. Plan the future in psychological term namely is Future Orientation. In this study, perceived parenting is a term which includes describing a positive relationship between parents with adolescents which includes the involvement or acceptance of parents towards adolescents, strict attitudes and parental supervision, parents limit the environment of adolescents, parents giving adolescents the freedom to be autonomy. (Chao, 2001; Gray \& Steinberg, 1989; Steinberg, Lamborn, Dornbusch, \& Darling, 1992 in Seginer, 2009).

The research question is "Are there differences in perceived parenting and future orientation in two areas with 


\section{dufferent association to arts and culture in Bandung regency ?" \\ II. METHOD OF RESEARCH}

This study is a cross-sectional study comparative study to find out the differences in perception of adolescents to the parents and future orientation of adolescents. The crosssectional study was choosen because the study conducted at one time and once, no follow-up, to find the relationship between the independent variable and the dependent variable, namely between perceived parenting and future orientation of adolescents.

Perceived Parenting is how does perceive the adolescents about the parenting that describing positive relationship between father and mother with adolescents that parental involving or parental acceptance to adolescents, strict behavior and parental control, limit their enviromental, parent give freedom to adolescents for independent behavior. Acceptance is affection expression from parents to adolescents, parents concern that showed to adolescents's problems, doing activities together between parents and adolescents, and parent giving help to adolescents. Supervision parents concern to knowing and controlling adolescents's interests, needs, problems, and achievements. Limit setting is parent's behavior in setting the rule and limitation to adolescents enviromental. Autonomy granting parent's behavior giving freedom and independent to adolescents.

Future Orientation is a picture of the individual model in the future. This concept provides how adolescents set goals, plan, choose and do exploration, make commitments and result in providing guidance for self-development. Of the three basic components forming future orientation is a motivation, planning and evaluation. From this definition, it can be understood that future orientation is an individual concept of the future that is in the minds of adolescents related to how adolescents set goals, plan, choose and carry out exploration, and make commitments.

Data collecting was carried out on 117 students in Junior High School in Bandung Regency. The data obtained were calculated using an independent sample t-test using SPSS for windows.

\section{RESULT}

TABEL I.. PERCEIVED PARENTING AND FUTURE ORIENTATION

\begin{tabular}{|l|l|}
\multicolumn{2}{c}{ IN JELEKONG } \\
\hline Variable & Mean \\
\hline Father perceived parenting & 2.32 \\
\hline Mother perceived parenting & 2.36 \\
\hline Future Orientation & 2.73 \\
\hline
\end{tabular}

TABEL II. PERCEIVED PARENTING AND FUTURE ORIENTATION IN ARJASARI

\begin{tabular}{|l|l|}
\hline Variable & Mean \\
\hline Father perceived parenting & 2.26 \\
\hline Mother perceived parenting & 2.53 \\
\hline Future Orientation & 2.03 \\
\hline
\end{tabular}

Based on tabel I and tabel II, father perceived parenting in Jelekong is to be low. mother perceived parenting is low and thus the future orientation is low. Whereas in Arjasari, father perceived parenting is low, mother perceived parenting is high and thus the future orientation is high.

IV. DISCUSSION

Based on the result, the comparative study showed that comparing similiraties and differences to look for what factors can cause to future orientation and perceived parenting of adolescent in two area different association. Therefore, we conclude that the perceived parenting and future orientation of adolescent in Arjasari more higher than Jelekong. According to Becker, Sarah etc (2019) parenting related to education during secondary school predicts latent classes that are different from life purpose regulations. Result of the discussion for the next research, it can be seen how the relationship between parental, social context, parental welfare and environmental factors influences future orientation. According to Edward, Erick De Donato (2014) there is a relationship between the social context in the future orientation with expectations regarding higher education. Mayer, B. Kuramschew, Trommsdorf (2018) explain that there is a relationship between family values and the future orientation of adolescent domain families. Future orientation of adolescent family domain is important and related to the desire to have children in the future. Research into the future orientation of the family domain is related to the cultural values that develop in the family. Research can also be conducted on the sexes of male and female students respectively. Future orientation research is conducted on adolescents of both sexes. (Mayer, B. Kuramschew, Trommsdorf, 2018). According to Biglan, Anthony and Holmes, Yvonne Barnes (2015) There is a relationship between planning in the future and prosperity in the future.

\section{CONCLUSION}

Based on the results of research and discussion, comparative studies show that comparing similarities and differences to find out what factors can lead to future orientation and perceived parenting patterns in adolescents in two different social areas. Thus it can be concluded that the perception of upbringing patterns and future orientation of adolescents in Arjasari is higher than in Jelekong.

\section{REFERENCES}

[1] Becker, Sarah Fpost, Maximilian, Sciefer, Irene. M. Artelt, Cordula 2019. Relations between life-goal regulation, goal orientation, and education-related parenting - A person-centered perspective. Learing and Individual Differencies. Volume 76. Desember 2019. 101786. Elsevier.

[2] Biglan, Anthony and Holmes, Yvonne Barnes. 2015. Acting in Light of the Future: How Do Future-Oriented Cultural Practices Evolve and How Can We Accelerate Their Evolution?

[3] Edward Erick De Donato. 2014. The Role of Social Context on Future Orientation and College Preparatory Behaviors Among Texas High School Students: LatinoWhite Differences

[4] Lindstorm, Sarah Johnson, Blum, Robert W, Cheng, Tina : 2014 Future Orientation : A Construct with implications for adolescent health and wellbeing. International Journal of Adolescent Medicine and Health. 
[5] Mayer, B. Kuramschew, Trommsdorf, 2018. Family-related values and future orientation in adolescence: A German- Russian comparison. http://www.researchgate.net/publication/281981024

[6] McCabe, Kristen M. Barnett, Douglass. 2000 The Relation Between Familial Factors and the Future Orientation of Urban, African American Sixth Graders. Link Springer.com

[7] Newman, Barbara M. and Newman, Philip R. 2015. Development Through Life: A Psychological Approach. Twelfth Edition. Cengage

[8] Learning. USA

[9] Nurmi, J. E. 1991. How do adolescents see their future? A review of the development of future orientation and planning. APA PsycNet.

[10] Santrock, John. 2007. Adolescence. Twelfth Edition. McGraw-Hill Education

[11] Seginer. Rachel. 2009. Future Orientation. Developmental and Ecological Perspectives. Springer

[12] Seginer, Rachel \& Lilach, Efrat. 2004. How Adolescents Construct Their Future: The Effect of Loneliness on Future Orientation. Journal of Adolescence 27. 2004. available online at www.sciencedirect.com

[13] Steinberg. Laurence D. 2013. Adolescence. Tenth Edition. McGraw-Hill.

[14] BPS. 2018. Jumlah Penduduk Berdasarkan Usia Pendidikan. http://data.bandung.go.id/group/kependudukan 